\title{
Editorial for the Topical Issue "Thermal analysis and calorimetry techniques applied to the characterization of materials and fluids for energy"
}

\author{
Christine Dalmazzone* \\ IFP Energies nouvelles, Applied Physical Chemistry and Mechanics Division, 1 et 4, Avenue de Bois-Préau, \\ 92852 Rueil-Malmaison, France
}

Received: 28 June 2019 / Accepted: 11 July 2019

From May 29 to June 1, 2017, IFP Energies nouvelles has organized the "JCAT48", Calorimetry and Thermal Analysis Days, under the auspices of the French Association of Calorimetry and Thermal Analysis (AFCAT).

Calorimetry and thermal analysis are universally recognized techniques for the characterization of fluids and materials in Chemistry, Physics and Biology. They make it possible to have access to the evolution of matter with time, temperature or pressure.

The key topic for this new edition was "thermal analysis and calorimetry techniques applied to the characterization of materials and fluids for energy".

Progress in the characterization of these systems is a major challenge for the development of new processes that will ensure the energy transition. The techniques of thermal analysis and calorimetry, which can be easily coupled with many other characterization techniques, are a powerful tool for accessing the physicochemical, thermophysical, thermodynamic and chemical kinetics properties of various systems.

Among the main fluids of interest, mention can be made of petroleum products (oil, gas, fuels), those resulting from the conversion of biomass (bio-oils and biofuels), as well as colloidal systems (emulsions, microemulsions, hydrate suspensions, etc.).

The materials concerned are catalysts, zeolites, MOFs, adsorbents, native biomass, rocks, amorphous and semicrystalline polymers, composites, organic deposits, etc.

Applications range from energy production and storage (thermal or chemical) to engine applications as to $\mathrm{CO}_{2}$ capture and storage.

In this special issue of the OGST journal, we have grouped together a few articles highlighting the importance of thermodynamic and physicochemical data acquisition in characterizing and predicting the behavior of complex systems of interest for new energy applications.

\footnotetext{
* Corresponding author: christine.dalmazzone@ifpen.fr
}

The first article entitled "Characterization of Complex Crude Oil Microemulsions-DSC Contribution" by [1] presents how Differential Scanning Calorimetry (DSC) can be used to provide information on the physico-chemical composition of complex microemulsions (water and oil content, salinity, etc.) and on their morphology (continuous phase, dispersed phase, etc.). This type of information is of prime importance to model the behavior of crude oil microemulsions formed during surfactant flooding, a chemical enhanced oil recovery (EOR) process which consists in injecting optimized formulations of surfactants in a reservoir in order to remobilize the residual oil trapped in the pores of the rock.

The next one, "DSC (Differential Scanning Calorimetry) used to follow the evolution of $\mathrm{W} / \mathrm{O}$ emulsions versus time on ground and in space in the ISS" by [2] gives some new insight on the evolution of $\mathrm{W} / \mathrm{O}$ emulsions versus time in microgravity conditions. This study was performed in the framework of the FASES (Fundamental and Applied Studies on Emulsion Stability) project sponsored by the European Space Agency (ESA). The objective was to use calorimetry to investigate the stability of $\mathrm{W} / \mathrm{O}$ emulsions under purely diffusive conditions (no gravity driven effects) and to compare it with the stability of similar emulsions observed on ground. For that purpose, two identical calorimeters were built by Airbus (formerly EADS) with the support of the French company SETARAM: The Flight Model (FM) located onboard the International Space Station (ISS) and the Engineering Model (EM) located at the TELESPAZIO Centre in Naples.

The article entitled "Excess/deviation properties of binary mixtures of 2,5-dimethylfuran with furfuryl alcohol, methyl isobutyl ketone, 1-butanol and 2-butanol at temperature range of (293.15-323.15) K" by [3] gives some new thermodynamic properties of binary mixtures of fluids representative of new fuels derived from biomass. These thermodynamic properties were used to interpret the molecular interactions among the different liquid components. The values of excess/deviation functions have been 
fitted to Redlich-Kister type polynomial equation. From these results, a discussion was carried out in terms of nature of intermolecular interactions and structure factors in the binary mixtures.

Finally, the article "Differential Scanning Calorimetry contribution to a better understanding of the aging of gelled waxy crude oils" by [4] concerns the characterization of the behavior of gelled waxy crude oils, which is a concern of prime importance for flow assurance during crude oil production. In this study, a set of rheological tests and calorimetric analysis were performed on a real waxy crude oil. The experimental results confirm that a gel formed with waxy crystals may evolve with time and that the extent of this phenomenon depends on the thermo-mechanical history of the sample.

In conclusion, thermal analysis and calorimetry techniques are essential to progress in the characterization of fluids and materials of interest for energy. In the context of energy transition, there is no doubt that these techniques, which can be advantageously coupled with other types of analytical techniques (spectroscopic for example), will make it possible to respond effectively to the growing need for thermodynamic and physico-chemical data to understand, describe, model and predict the behaviour of new fluids and materials under development.

\section{References}

1 Fukumoto A., Dalmazzone C., Frot D., Barré L., Noïk C. (2018) Characterization of Complex Crude Oil MicroemulsionsDSC Contribution, Oil Gas Sci. Technol. - Rev. IFP Energies nouvelles $\mathbf{7 3}, 3$.

2 Drelich A., Dalmazzone C., Pezron I., Liggieri L., Clausse D. (2018) DSC (Differential Scanning Calorimetry) used to follow the evolution of $\mathrm{W} / \mathrm{O}$ emulsions versus time on ground and in space in the ISS, Oil Gas Sci. Technol. - Rev. IFP Energies nouvelles $\mathbf{7 3}, 16$.

3 Mahi M.R., Ouaar F., Negadi A., Bahadur I., Negadi L. (2018) Excess/deviation properties of binary mixtures of 2,5-dimethylfuran with furfuryl alcohol, methyl isobutyl ketone, 1-butanol and 2-butanol at temperature range of (293.15-323.15) K, Oil Gas Sci. Technol. - Rev. IFP Energies nouvelles 73, 64 .

4 Henaut I., Betro B., Vinay G. (2019) Differential Scanning Calorimetry contribution to a better understanding of the aging of gelled waxy crude oils, Oil Gas Sci. Technol. - Rev. IFP Energies nouvelles 74, 16. 